\title{
Formation and Properties of the Lyotropic Mesophase of the Cellulose/Mixed Inorganic Acid System
}

\author{
Kenji Kamide, Ikuya MiYamoto, and Kunihiko OKaJima \\ Fundamental Research Laboratory of Fibers and Fiber-Forming Polymers, \\ Asahi Chemical Industry Co., Ltd., 11-7 \\ Hacchonawate, Takatsuki, Osaka 569, Japan.
}

(Received June 29, 1992)

\begin{abstract}
As an extension of a previous study [K. Kamide, K. Okajima, T. Matsui, and S. Kajita, Polym. J., 18, 273 (1986)] on lyotropic mesophases of cellulose derivatives in aq. inorganic acid systems, the lyotropic mesophase of cellulose was studied in a mixture of sulfuric acid (SA)/polyphosphoric acid (PPA)/water (W). It was found that SA/PPA/W mixture with a specific composition (SA/PPA/W $=c a .1 / 8 / 1, \mathrm{w} / \mathrm{w} / \mathrm{w}$ ) gave mesophase solution of cellulose. The mesophase had a cholesteric nature as detected by circular dichroism and the cellulose in the system was not derivatized over the whole range of storage time (less than $48 \mathrm{~h}$ ). A Raman spectroscopic study of the solvent mixtures revealed that the hydrolysis of polyphosphoric acid may be restricted in specific composition. Polarized IR study clarified that $\mathrm{C}-\mathrm{O}$ stretching vibrations of the cellulose molecules in the film, cast from the mesophase solution, are oriented perpendicularly to the shear direction imposed on the mesophase in its film casting process. This phenomenon was not observed for the films prepared from isotropic solution of the same system.
\end{abstract}

KEY WORDS Cellulose Liquid Crystal / Mesophase / Inorganic Acid Mixture / Polarized IR / Circular Dichroism / Molecular Orientation /

As is well-recognized, cellulose and its derivatives can form lyotropic liquid crystals when dissolved in appropriate solvents. Werbowyj and $\mathrm{Gray}^{1}$ reported on the lyotropic liquid crystals of hydroxypropyl cellulose/water systems. Maeno, who may be the first who discovered the liquid crystals of cellulose derivatives, applied a patent of an optical device using the liquid crystals prepared from cellulose ethers/solvent systems. ${ }^{2}$ Panar and Willcox ${ }^{3}$ found the formation of the liquid crystals by cellulose derivatives such as cellulose ethers and cellulose esters with a total degree of substitution $\langle\mathrm{F}\rangle$ more than 1 in their appropriate solvent (mainly organic solvent). In addition, some solvent systems in which cellulose can form liquid crystal have been reported: $N$-methylmorpholine $N$-oxide (MMNO) $/$ water $^{4}{ }^{4}$ dimethylacetamide/lithium chloride, ${ }^{5}$ trifluoroacetic acid (TFA)/halogen- ated hydrocarbons $(\mathrm{HH}),{ }^{6}$ liquid ammonia (liq. $\mathrm{NH}_{3}$ )/ammonium thiocyanate $\left(\mathrm{NH}_{4} \mathrm{SCN}\right)$ /water. ${ }^{7}$ Cuculo et al. pointed out that the cellulose liquid crystal in liq. $\mathrm{NH}_{3} / \mathrm{NH}_{4} \mathrm{SCN} /$ water exhibited both nematic and cholesteric structures depending on the composition of the solvent component ${ }^{8}$ and that cellulose molecules in the film coagulated and regenerated from anisotropic solution are oriented in the direction of shear imposed on the solution ${ }^{7}$. Gilbert ${ }^{6}$ showed by optical rotatory study that cellulose dissolved in TFA/halogenated hydrocarbons was the cholesteric liquid crystal.

The possibility of the production of fiber with high breaking strength (TS) and high Young's modulus from lyotropic liquid crystals by applying the so-called liquid crystal spinning method attracts keen interest in industry. Extensive studies have been made on cellulose 
liquid crystal spinning: Quenin ${ }^{9}$ prepared a cellulose fiber with TS of 6 gram $(\mathrm{g}) /$ denier $(d$, weight of fiber with $9000 \mathrm{~m}$ in length) from cellulose/MMNO/water system by dry-jet, wet spinning method. Yang ${ }^{8}$ obtained a cellulose fiber with $\mathrm{TS}$ of $3 \mathrm{gd}^{-1}$ from cellulose/liq. $\mathrm{NH}_{3} / \mathrm{NH}_{4} \mathrm{SCN}$ system by the same spinning method as that used by Quenin. A regenerated cellulose fiber with high TS $\left(18 \mathrm{~g} \mathrm{~d}^{-1}\right)$ was successfully produced by O'Brien who saponified the cellulose triacetate (CTA) fiber (TS $\left.=15 \mathrm{gd}^{-1}\right)$ spun from CTA/TFA/HH liquid crystal system. ${ }^{10}$ However, the organic solvents used for the formation of cellulosic liquid crystals have serious drawbacks such as high cost, high toxicity, and difficulty of solvent recovery.

Kamide et al. ${ }^{11}$ suggest the possibility of the formation of lyotropic liquid crystal of cellulose derivatives, showing that conformation parameter, which is a measure of molecular chain rigidity, of cellulose acetate dissolved in solvent became larger when a solvent with high polarity was used. On the basis of the above suggestion, they studied on the formation of cellulosic liquid crystals by aq. inorganic acids as high polar solvents. As a result, Kamide, Okajima and their coworkers ${ }^{12,13}$ found that most cellulose derivatives with wide varieties of $\langle F\rangle$ range (including $\langle\langle\mathrm{F}\rangle\langle<1$ ) could form liquid crystals in aq. inorganic acids. Furthermore, they reported that cellulose diacetate (CDA) fibers with relatively lower degree of polymerization $(\mathrm{DP}=170)$ spun from $\mathrm{CDA} / 70 \mathrm{wt} \%$ aq. nitric acid liquid crystal system had far higher TS than commercially available CDA fibers. ${ }^{14}$ However, in spite of considerable effort no inorganic acid system is known to form cellulose liquid crystals. This point motivated us.

In this study, the formation of the cellulose liquid crystal in a specific combination of inorganic acid mixture (sulfuric acid (SA)/polyphosphoric acid (PPA)/water (W)), properties of liquid crystal solution and super-molecular structures of films recovered from the liquid crystal solutions will be discussed.

\section{EXPERIMENTAL}

\section{Cellulose Sample}

Soft wood pulp (Alaska pulp, manufactured by Alaska Pulp Co. (U.S.A.): $\alpha$-cellulose content, $90.1 \mathrm{wt} \%$; the viscosity-average molecular weight $M_{v}=1.72 \times 10^{5}$ ), which was exploded according to the procedure described in the previous paper ${ }^{15}$ was employed as the cellulose sample. $M_{v}$ of the sample was $5.36 \times 10^{4}$, as determined from the limiting viscosity number $[\eta] \mathrm{g} \mathrm{ml}^{-1}$ in cadoxen (cadmium oxide/ethylenediamine $/ \mathrm{NaOH} / \mathrm{H}_{2} \mathrm{O}=5$ / $28 / 1.4 / 166, \mathrm{w} / \mathrm{w} / \mathrm{w} / \mathrm{w})$ at $25^{\circ} \mathrm{C}$ using the following equation ${ }^{16}$ :

$$
[\eta]=3.85 \times 10^{-2} M_{w}^{0.76}
$$

where $M_{w}$ is the weight-average molecular weight.

\section{Inorganic Acids}

Guaranteed grade $97 \mathrm{wt} \%$ sulfuric acid (density: 1.840 , denoted as SA component) and $100 \mathrm{wt} \%$ polyphosphoric acid $\left(\mathrm{H}_{6} \mathrm{P}_{4} \mathrm{O}_{13}\right.$, denoted as PPA component) were supplied by Wako Chemicals Co., Ltd. (Japan) and deionized water (denoted as $\mathrm{W}$ component) with electric conductivity $\sigma<0.3 \mu \mathrm{S} \mathrm{cm}^{-1}$ (S, Siemens or mho) was prepared through ion-exchange resin. Mixtures with various compositions of sulfuric acid (SA)/polyphosphoric acid (PPA)/water (W) were prepared, stored at $-5^{\circ} \mathrm{C}$ and used for solubility tests of cellulose and the formation of the lyotropic mesophase of cellulose.

\section{Solubility Test of Cellulose in Sulfuric Acid $(S A) /$} Polyphosphoric Acid(PPA)/Water $(W)$

Ternary mixtures (polymer concentration $C_{\mathrm{p}}=5 \mathrm{wt} \%$ ) were prepared from cellulose and SA/PPA/W mixed solvents of all compositions and stored at $-5^{\circ} \mathrm{C}$. In order to find the composition of a mixed solvent in which 
cellulose shows good solubility, change in the dissolved state of mixtures was visually observed at various storage times $t_{\mathrm{s}}\left(t_{\mathrm{s}}: 24 \mathrm{~h}\right.$, $48 \mathrm{~h}, 110 \mathrm{~h}, 400 \mathrm{~h})$. In this test, the ternary mixtures could be classified into four categories as soluble, partially soluble, insoluble, and degradable.

\section{Preparation and Microscopic Observation of Mesophase Solutions \\ Cellulose was mixed with the SA/PPA/W} system at $-5^{\circ} \mathrm{C}$, whose composition allows dissolution of cellulose to give a solution with $C_{\mathrm{p}}$ ranging between $10-20 \mathrm{wt} \%$ and mixtures stood for two days at $-5^{\circ} \mathrm{C}$. The resultant solutions were placed between a slide glass and cover glass and observed under an optical microscope with crossed nicol at $25^{\circ} \mathrm{C}$ with sliding cover glass moved in an arbitrary direction by the finger. For solution, the relaxation time, the period needed for decay of bright view, was roughly estimated. A solution whose relaxation time was longer than $60 \mathrm{~s}$ was regarded for convenience as the lyotropic mesophase.

\section{Circular Dichroism of Mesophase Solution}

Cellulose mesophase $\left(C_{\mathrm{p}}=18 \mathrm{wt} \%, \mathrm{SA} /\right.$ PPA $/ \mathrm{W}=1 / 8 / 1, \mathrm{w} / \mathrm{w} / \mathrm{w})$ was placed between two quartz plates, separated with a spacer (thickness, $5 \mu \mathrm{m}$ ). Circular dichroism (CD) of the mesophase solution was measured at $0^{\circ} \mathrm{C}$ as a function of standing time $t_{\mathrm{CD}}$ using a CD (ORD) spectropolarimeter (J-720 type, JAS$\mathrm{CO}$, Japan). Here, $t_{\mathrm{CD}}=0$ is defined as the time the solution is placed between two quartz plates.

The cholesteric pitch $(P)$ is expressed by the relation. ${ }^{17}$

$$
P=m \lambda_{0} / \bar{n} \sin \theta
$$

where $m$ is an integer, $\lambda_{0}$ is the maximum wavelength of the observed $\mathrm{CD}$ peak, $\bar{n}$, average refractive index of the mesophase solution, $\theta$, an angle between the direction of the incident beam and the plane of the cholesteric layer. For incident light perpendicular to the plane $\left(\theta=90^{\circ}\right)$ and $m=1$, eq 2 is simiplified to give

$$
P=\lambda_{0} / \bar{n}
$$

and $P$ was estimated using eq 3 . Here, $\bar{n}$ was measured at $0^{\circ} \mathrm{C}$ with an $\mathrm{Abbe}$ refractometer.

\section{${ }^{13}$ C NMR Measurement}

Two regenerated cellulose film samples (a-film and i-film) were prepared by pouring anisotropic and isotropic solutions into excess methanol $\left(C_{\mathrm{p}}=18 \mathrm{wt} \%, \mathrm{SA} / \mathrm{PPA} / \mathrm{W}=1 / 8 / 1\right.$ and $3 / 4 / 3(\mathrm{w} / \mathrm{w} / \mathrm{w})$ respectively). The films were washed thoroughly with aq. $\mathrm{NaHCO}_{3}$ solutions and water and dried. Solid-state ${ }^{13} \mathrm{C}$ NMR spectra of these samples were recorded on a FT-NMR spectrometer (FX-200 (50.1 $\mathrm{MHz}$ for ${ }^{13} \mathrm{C}$ nucleus), JEOL Ltd., Japan) under the following conditions: Data points, 8192 (4096 zero-filling); accumulation, 2001024; pulse width, $5.5 \mu \mathrm{s}$; contact time, $2 \mathrm{~ms}$; pulse interval, $5 \mathrm{~s}$; spectral width, $20000 \mathrm{~Hz}$.

The degree of break-down of $\mathrm{O}_{3} \mathrm{H} \cdots \mathrm{O}_{5}{ }^{\prime}$ intramolecular hydrogen bonds $\chi_{\mathrm{am}}\left(\mathrm{C}_{3}\right)$ was estimated using the equation proposed by Kamide and Okajima ${ }^{18}$ :

$$
\chi_{\mathrm{am}}\left(C_{3}\right)=100 \times\left\{I_{\mathrm{h}} /\left(I_{\mathrm{h}}+I_{1}\right)\right\}(\%)
$$

Here, $I_{\mathrm{h}}$ and $I_{1}$ are the fractions of higher and lower magnetic peaks in the $\mathrm{C}_{4}$ peak region, respectively.

${ }^{13} \mathrm{C}$ NMR measurements were carried out on $9.1 \mathrm{wt} \%$ aq $\mathrm{NaOH}$ solutions of a-film and i-film using a FT-NMR spectrometer (GSX400 (100.2 MHz for ${ }^{13} \mathrm{C}$ nucleus), JEOL Ltd., Japan) under the following conditions: Data points, 32728; accumulation, 15000-20000; pulse interval, $5 \mathrm{~s}$; spectral width, $25000 \mathrm{~Hz}$; internal standard, sodium 3-trimethylsilylpropionate (TSP).

\section{FT-IR Measurement}

Polarized FT-IR spectra of the a-film and i-film were recorded by a transmission method on a JEOL FT-IR spectrometer (JIR 3505). 
The polarizer was set at various polarizer angles $\theta_{\mathrm{IR}}\left(0^{\circ}-90^{\circ}\right)$ against shear direction (denoted as $0^{\circ}$ ) imposed on the solutions in the film casting process. To evaluate the dichroism of the IR band, the molecular orientation factor $\left(f^{\|}\right)$in a parallel to shear direction for the characteristic IR bands was calculated using the relation. ${ }^{19}$

$$
f^{\|}=A^{\|} /\left(A^{\|}+2 A^{\perp}\right)
$$

Here, $A^{\|}$is absorbance of the IR band when $\theta_{\mathrm{IR}}=0^{\circ}$, and $A^{\perp}$ is the absorbance of the same band at $\theta_{\mathrm{IR}}=90^{\circ}$.

\section{Raman Spectroscopy}

Raman spectra for the binary mixtures of PPA and water (referred to as PPA/W) and ternary mixtures (SA/PPA/W) and phosphoric acid placed in glass tube were recorded on an Argon laser Raman spectrophotometer (JRS400, JEOL, Japan).

\section{RESULTS AND DISCUSSION}

Figure 1 shows phase diagrams for the solubility of cellulose $\left(C_{\mathrm{p}}=5 \mathrm{wt} \%\right)$ in the
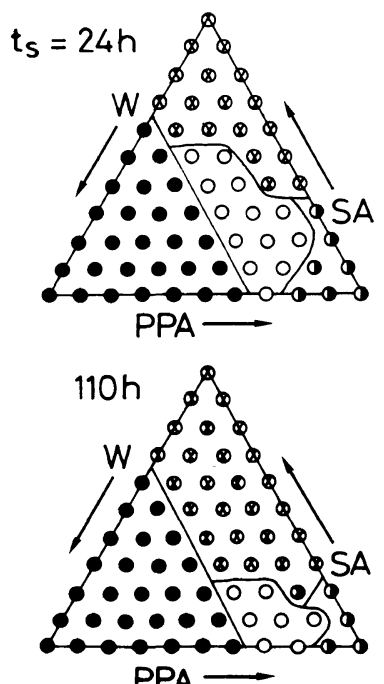

PPA $\longrightarrow$
SA/PPA/W system at various storage time $t_{\mathrm{s}}$. The insoluble region $(\mathrm{W} \geqq 0.4)$ did not practically alter with storage time $\left(t_{\mathrm{s}}\right)$ of the mixture. The region in which cellulose degraded expanded with increase in $t_{\mathrm{s}}$ to the region with lower SA (higher PPA) composition, and the region in which cellulose dissolved narrowed. At $t_{\mathrm{s}}=400 \mathrm{~h}$, the composition of the SA/ PPA/W system exhibiting solubility of cellulose was limited in the range of higher PPA ( $\geqq c a$. $0.6)$ and lower SA ( $\leqq c a .0 .2)$. These findings suggested that in the SA/PPA/W system with higher PPA content, the decomposition of cellulose is suppressed during storage. We examined the ability to form mesophase solution for the SA/PPA/W system with the compositions of $\mathrm{SA} \leqq 0.5, \mathrm{PPA} \geqq 0.3, \mathrm{~W} \leqq 0.4$.

Figure 2 shows the phase diagram of cellulose/SA/PPA/W system $\left(C_{\mathrm{p}}=18 \mathrm{wt} \%\right)$ at $t_{\mathrm{s}}=48 \mathrm{~h}$. A bright view was observed under the shear in relatively wide area of SA/PPA/W composition (as shown by the shadowed area in the figure). With increasing PPA content in the solvent mixture, the relaxation time increased and at a very specific composition $(\mathrm{SA} / \mathrm{PPA} / \mathrm{W}=c a .1 / c a .8 / c a .1, \mathrm{w} / \mathrm{w} / \mathrm{w}($ closed

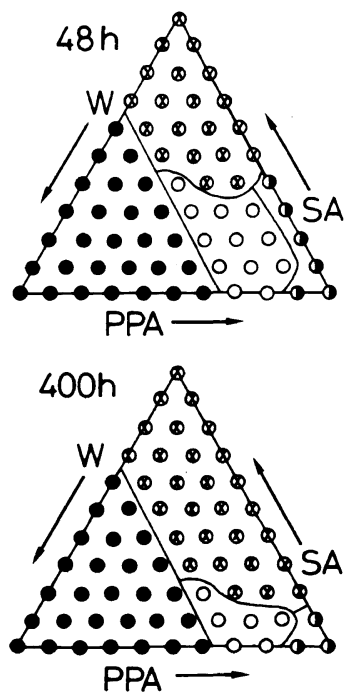

Figure 1. Phase diagrams for solubility of cellulose in sulfuric acid (SA)/polyphosphoric acid (PPA)/water (W) system $\left(C_{\mathrm{p}}=5 \mathrm{wt} \%\right)$ at various storage times $t_{\mathrm{s}}$ : $\bigcirc$, soluble; $\bigcirc$, partially soluble, $\bigcirc$, insoluble; $\otimes$, degraded. 


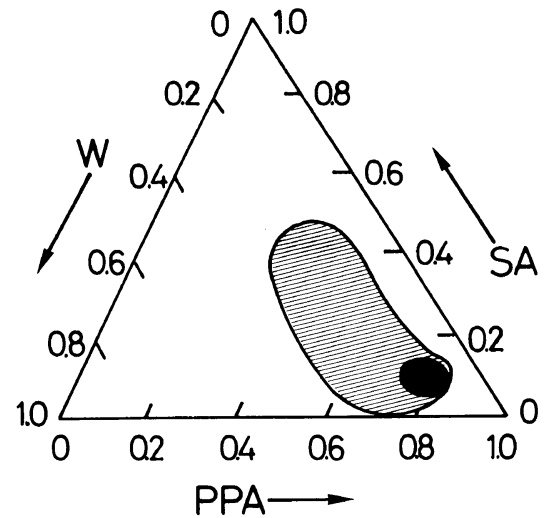

Figure 2. Phase diagram of cellulose in SA/PPA/W system $\left(C_{\mathrm{p}}=18 \mathrm{wt} \%\right)$ : shadowed area; isotropic phase, closed area; anisotropic phase (SA/PPA/W $=1 / 8 / 1, w / w / w$, $\left.t_{\mathrm{s}}=48 \mathrm{~h}\right)$.

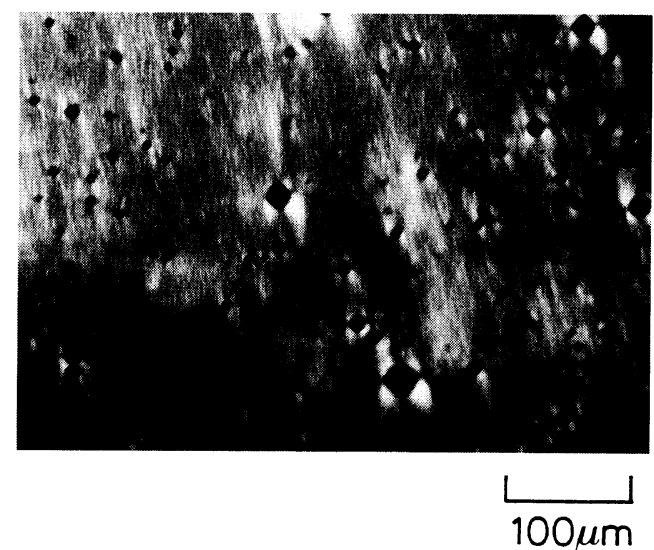

Figure 3. Optical microgram of anisotropic solution of cellulose $\left(C_{\mathrm{p}}=18 \mathrm{wt} \%\right.$ in SA/PPA/W $\left.(1 / 8 / 1), \mathrm{w} / \mathrm{w} / \mathrm{w}\right)$ system.

circle)), birefringence did not relax within at least 60 s. Over the whole area shadowed in Figure 2, except for the closed circle corresponding to the above specific composition, birefringence quickly relaxed within $0.1 \mathrm{~s}$. Only at a specific composition, cellulose could give anisotropic solution. The photomicrograph of this anisotropic solution is shown in Figure 3. Navard et al. reported ${ }^{20}$ for CTA/TFA system that the relaxation time $(\tau)$ of bright view induced by shear is remarkably different between anisotropic and isotropic solutions

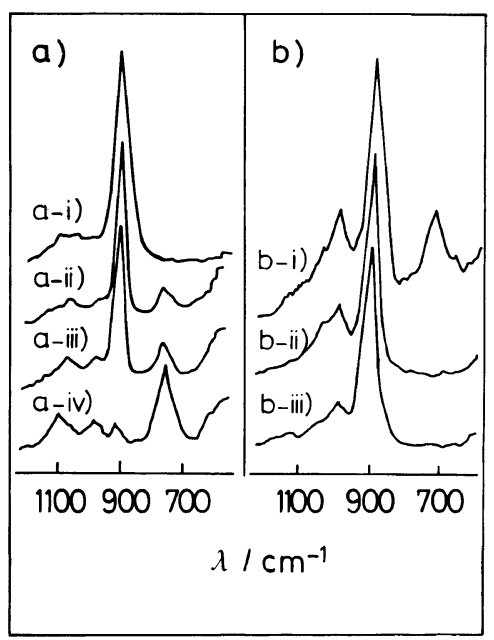

Figure 4. Raman spectra of aq. polyphosphoric acid and phosphoric acid (a): and SA/PPA/W mixtures (b): (a-i) phosphoric acid, (a-ii) $40 \mathrm{wt} \%$ aq. polyphosphoric acid, (a-iii) $51 \mathrm{wt} \%$ aq. polyphosphoric acid, (a-iv) $100 \mathrm{wt} \%$ polyphosphoric acid, (b-i) $\mathrm{SA} / \mathrm{PPA} / \mathrm{W}=1 / 8 / 1$, (b-ii) $\mathrm{SA} / \mathrm{PPA} / \mathrm{W}=2 / 7 / 1$, (b-iii) SA/PPA $/ \mathrm{W}=1 / 7 / 2(\mathrm{w} / \mathrm{w} / \mathrm{w})$.

(i.e., $\tau \sim 65 \mathrm{~s}$ for the former and $\tau<0.2 \mathrm{~s}$ for the latter).

The minimum cellulose concentration $\left(C_{\mathrm{pmin}}\right)$ needed for the formation of anisotropic phase at the composition of SA/PPA/W $=1 / 8 / 1$ was $16 \mathrm{wt} \%$. Cellulose in the solvent mixtures of other compositions never gave the anisotropic phase even if $C_{p}$ was increased to $20 \mathrm{wt} \%$. Therefore, it was experimentally confirmed that the composition of the solvent mixture is closely related to the formation of the lyotropic mesophase of cellulose.

The mixed solvent with the specific composition $(\mathrm{SA} / \mathrm{PPA} / \mathrm{W}=1 / 8 / 1, \mathrm{w} / \mathrm{w} / \mathrm{w})$ proved to form easily a white viscous precipitate on standing at $-10^{\circ} \mathrm{C}$, while different compositions did not bring about such a precipitate. This strongly suggests that the SA/PPA/W mixed solvent with the composition of $\mathrm{SA} / \mathrm{PPA} / \mathrm{W}=1 / 8 / 1 \quad(\mathrm{w} / \mathrm{w} / \mathrm{w})$ may form a characteristic structure.

Figure 4a shows Raman spectra of PPA/W mixtures with three different compositions (a-ii-iv) and phosphoric acid (a-i). Figure $4 b$ 
shows Raman spectra of SA/PPA/W mixtures with three compositions (SA/PPA/W $=1 / 8 / 1$, $2 / 7 / 1$, and $1 / 7 / 2, w / w / w)$ (b-i-iii). A Raman band at $730 \mathrm{~cm}^{-1}$ may be characteristic to polymeric $\mathrm{P}-\mathrm{O}$ stretching because no band around at $730 \mathrm{~cm}^{-1}$ was observed for phosphoric acid (see, Figure 4 a-i). With decrease in PPA concentration, the intensity of the $730 \mathrm{~cm}^{-1}$ peak decreased, but the peak did not disppear in the range of PPA concentration decrease to $40 \mathrm{wt} \%$. On the other hand, the SA/PPA/W (SA/PPA/W $=2 / 7 / 1$ and $1 / 7 / 2$, $\mathrm{w} / \mathrm{w} / \mathrm{w}$ ) showed no band around at $730 \mathrm{~cm}^{-1}$ (see Figures $4 \mathrm{~b}$-ii, iii), suggesting that sulfuric acid in the system facilitates the hydrolysis of polymeric P-O bond. However, a band at $730 \mathrm{~cm}^{-1}$ was observed only in the SA/PPA/W system $(\mathrm{SA} / \mathrm{PPA} / \mathrm{W}=1 / 8 / 1, \mathrm{w} / \mathrm{w} / \mathrm{w})$ (see, Figure $4 b-i)$ which is capable of forming lyotropic mesophase of cellulose. These findings lead us to the conclusion that sulfuric acid in SA/PPA/W mixture might be fixed in PPA matrix at specific composition and does not play as a catalyst for the hydrolysis of PPA. Such a supermolecular structure of the SA/PPA/W system may be the principal criterion for the formation of lyotropic cellulose mesophase and experimental direct analysis of such structure is open for further study.

Kamide et al. ${ }^{12}$ first demonstrated that cellulose derivatives with total degree of substitution $\langle\mathrm{F}\rangle$ less than 1 could form lyotropic liquid crystals in inorganic acids and there remains the possibility that cellulose is partially derivatized in the SA/PPA/W liquid crystal system with specific composition (SA/PPA/ $\mathrm{W}=1 / 8 / 1, \mathrm{~W} / \mathrm{w} / \mathrm{w})$ and the cellulose derivatives formed in SA/PPA/W system build up the mesophase.

Figure 5 shows $\mathrm{CP} / \mathrm{MAS}$ solid state ${ }^{13} \mathrm{C}$ NMR spectra of the cellulose films (a-film and i-film) prepared from anisotropic solutions and isotropic solutions by coagulating with methanol. CP/MAS spectra for a- and i-films are principally the same and these spectra indicate

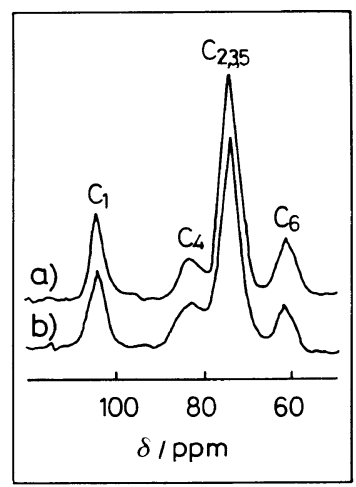

Figure 5. $\mathrm{CP} / \mathrm{MAS}{ }^{13} \mathrm{C}$ NMR spectra of the celluloses recovered from optically anisotropic solution (a) and isotropic solution (b): (a) $C_{\mathrm{p}}=18 \mathrm{wt} \%, \mathrm{SA} / \mathrm{PPA} / \mathrm{W}=1 / 8 / 1$, $\mathrm{w} / \mathrm{w} / \mathrm{w}$; (b) $C_{\mathrm{p}}=18 \mathrm{wt} \%, \mathrm{SA} / \mathrm{PPA} / \mathrm{W}=3 / 4 / 3$, w/w $/ \mathrm{w}$.

that both films are pure cellulose $\left(\mathrm{C}_{1}, 105 \mathrm{ppm}\right.$; $\mathrm{C}_{4}, 83 \mathrm{ppm} ; \mathrm{C}_{2}$ 3, and 5,74 ppm; $\left.\mathrm{C}_{6}, 63 \mathrm{ppm}\right)$. Note that methanol has no deesterification action. The possibility of derivatization is thus denied. For these cellulose films the degree of break-down in $\mathrm{O}_{3} \mathrm{H} \cdots \mathrm{O}_{5}^{\prime}$ intramolecular hydrogen bond $\chi_{\mathrm{am}}\left(\mathrm{C}_{3}\right)$ was estimated to be about $90 \%$. In other words, the coagulation method employed here gives a cellulose solid containing only a few intramolecular hydrogen bonds. Kamide et al. ${ }^{18,21}$ varified experimentally that the solubility of cellulose II is governed by $\chi_{\mathrm{am}}\left(\mathrm{C}_{3}\right)$ independent of DP ranging from 100 to 300 . Then, the above two cellulose samples recovered from SA/PPA/W system are expected to dissolve in a $9.1 \mathrm{wt} \%$ $\mathrm{NaOH}$ solution at low temperature, although DP of these samples was found by the viscometric method (through eq 1) to be 270 and 230 for a- and i-films respectively. The method adopted for preparation of a-and i-films may provide a powerful means to give alkali-soluble cellulose. In fact, the above two recovered films (a- and i-film) easily dissolved in aq $9.1 \mathrm{wt} \% \mathrm{NaOH}$ at $4{ }^{\circ} \mathrm{C}$.

In order to examine further the possibility of derivatization of cellulose in SA/PPA/W system, the solutions were subjected to ${ }^{13} \mathrm{C}$ NMR measurements. The results are shown in Figure 6, in which the spectrum of the 


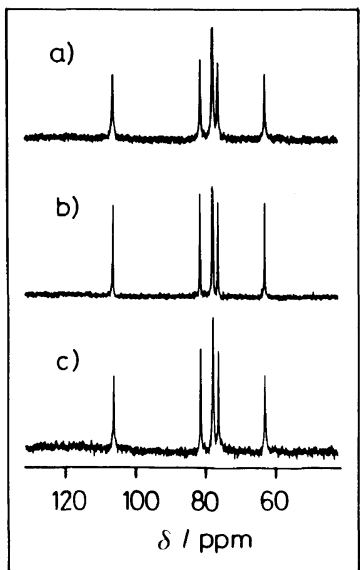

Figure 6. ${ }^{13} \mathrm{C}$ NMR spectra of recovered celluloses and starting cellulose dissolved in aq $9.1 \mathrm{wt} \%$ sodium hydroxide: (a) cellulose recovered from anisotropic solution $\left(C_{\mathrm{p}}=18 \mathrm{wt} \%, \mathrm{SA} / \mathrm{PPA} / \mathrm{W}=1 / 8 / 1, \mathrm{w} / \mathrm{w} / \mathrm{w}, t_{\mathrm{s}}=\right.$ $48 \mathrm{~h}$ ); (b) cellulose recovered from isotropic solution $\left(C_{\mathrm{p}}=18 \mathrm{wt} \%, \mathrm{SA} / \mathrm{PPA} / \mathrm{W}=3 / 4 / 3, \mathrm{w} / \mathrm{w} / \mathrm{w}, t_{\mathrm{s}}=48 \mathrm{~h}\right) ;(\mathrm{c})$ starting cellulose.

steam-exploded pulp in aq $9.1 \mathrm{wt} \% \mathrm{NaOH}$ is included for reference. ${ }^{13} \mathrm{C}$ NMR spectra of a- and i-film in a $9.1 \mathrm{wt} \% \mathrm{NaOH}$ solution show $\mathrm{C}_{1}$ peak at $106.5 \mathrm{ppm}, \mathrm{C}_{4}$ peak at $82.0 \mathrm{ppm}$, $\mathrm{C}_{3}, \mathrm{C}_{5}$ peak at 78.5 or $79.0 \mathrm{ppm} \mathrm{C}_{2}$ peak at $77.0 \mathrm{ppm}$ and $\mathrm{C}_{6}$ peak at $63.5 \mathrm{ppm}$, exhibiting the almost same spectra of the starting material cellulose. If cellulose could be derivatized in the SA/PPA/W system, cellulose sulfate or cellulose phosphate would be possible candidates, and if this is true, a new peak should appear at around $101-103 \mathrm{ppm}$ or $68-70$ ppm. But no such peak was detected. This is the second experimental evidence for no derivatization of cellulose in SA/PPA/W system.

Figure 7 shows $\mathrm{CD}$ spectra of cellulose lyotropic mesophase $\left(C_{\mathrm{p}}=18 \mathrm{wt} \%, \mathrm{SA} / \mathrm{PPA} /\right.$ $\mathrm{W}=1 / 8 / 1, \mathrm{w} / \mathrm{w} / \mathrm{w})$ measured at various standing times $t_{\mathrm{CD}}$. It is known that the appearance of $\mathrm{CD}$ peak provides direct evidence for the cholesteric mesophase. ${ }^{22}$ With increase in $t_{\mathrm{CD}}$, the spectrum for the present system became sharp and the intensity of the CD peak around at $510 \mathrm{~nm}\left(=\lambda_{0}\right)$ increased, approaching an asymptotic value at $t_{\mathrm{CD}}=120 \mathrm{~min}$. This in-

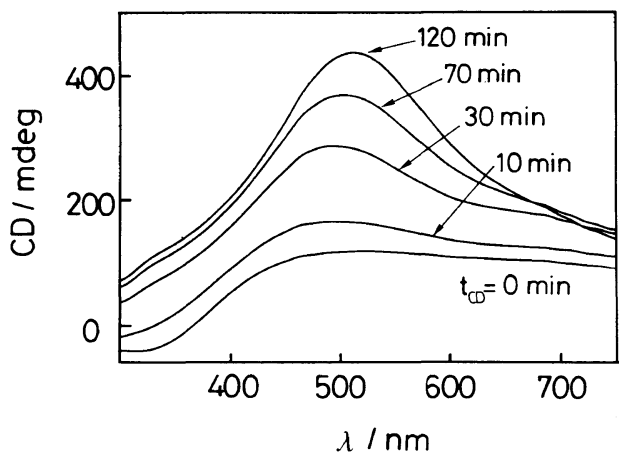

Figure 7. Circular dichroism (CD) spectra of the lyotropic mesophase of cellulose in SA/PPA/W mixture: $\left(C_{\mathrm{p}}=18 \quad \mathrm{wt} \%, \quad \mathrm{SA} / \mathrm{PPA} / \mathrm{W}=1 / 8 / 1, \quad \mathrm{w} / \mathrm{w} / \mathrm{w}\right)$, at $0^{\circ} \mathrm{C}$; standing time $t_{\mathrm{CD}}$ is given in the figure.

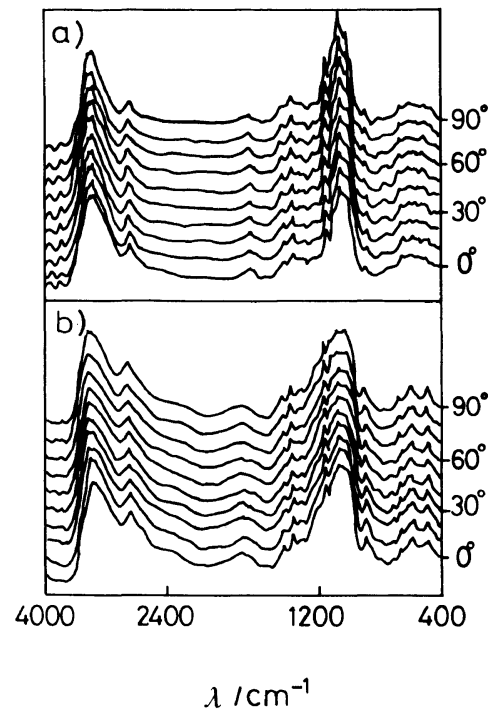

Figure 8. Polarized IR spectra for cellulose films recovered from optically anisotropic and isotropic solutions: (a) anisotropic solution $\left(C_{\mathrm{p}}=18 \mathrm{wt} \%, \mathrm{SA} /\right.$ $\mathrm{PPA} / \mathrm{W}=1 / 8 / 1, \mathrm{w} / \mathrm{w} / \mathrm{w}, t_{\mathrm{s}}=48 \mathrm{~h}$ ); (b) isotropic solution $\left(C_{\mathrm{p}}=18 \mathrm{wt} \%, \mathrm{SA} / \mathrm{PPA} / \mathrm{W}=3 / 4 / 3, \mathrm{w} / \mathrm{w} / \mathrm{w}, t_{\mathrm{s}}=48 \mathrm{~h}\right)$.

dicates that cellulose mesophase in the SA/PPA/W system has a cholesteric structure. Yamagishi ${ }^{23}$ observed that it takes a very long time for the thermotropic mesophase of cellulose derivatives to complete the formation of the cholesteric structure mainly due to its extremely high viscosity (for example, about one week at $60^{\circ} \mathrm{C}$ for cellulose- $\mathrm{O}\left(\mathrm{CH}_{2} \mathrm{CH}_{2} \mathrm{O}\right)_{3}$ 
$\mathrm{CH}_{3}$ ). The lyotropic mesophase of cellulose/ SA/PPA/W system also have very high viscosity and thus a few hours are necessary to recover the cholesteric structure after distortion by shear stress. The value of cholesteric pitch $(P)$ calculated from eq 3 using $\lambda_{0}=510 \mathrm{~nm}$ and $\bar{n}=1.459$ was $350 \mathrm{~nm}$. Obviously, $\lambda_{0}$ lies in the visible light region, corresponding to the appearance of the rainbow color of the mesophase solution. The CD peak in the positive side means the left-handed cholesteric structure.

Figure 8 shows the polarized IR spectra of a-film and i-film at various polarizer angles $\theta_{\mathrm{IR}}$ $\left(0 \sim 90^{\circ}\right)$ between the main axis of the polarizer and direction of shear applied to the solution, from which the films are regenerated. Table I

Table I. Infra-red dichroism of cellulose film recovered from sulfuric acid/polyphosphoric acid/water system

\begin{tabular}{|c|c|c|c|}
\hline \multirow{2}{*}{$\begin{array}{c}\text { Wave } \\
\text { number } \\
\mathrm{cm}^{-1}\end{array}$} & \multirow{2}{*}{ Assignment } & \multicolumn{2}{|c|}{$f^{\| \mathbf{a}}$} \\
\hline & & a-Film ${ }^{\text {b }}$ & i-Film ${ }^{c}$ \\
\hline 3475 & $\begin{array}{l}\text { OH(intra-molecular } \\
\text { hydrogen bond) }\end{array}$ & 0.336 & \\
\hline 3444 & $\begin{array}{l}\mathrm{OH}(\text { intra-molecular } \\
\text { hydrogen bond })^{\mathrm{d}}\end{array}$ & 0.344 & 0.342 \\
\hline 3440 & $\mathrm{OH}^{\mathrm{e}}$ & 0.353 & \\
\hline 3357 & $\begin{array}{l}\mathrm{OH} \text { (inter-molecular } \\
\text { hydrogen bond) }\end{array}$ & 0.354 & 0.350 \\
\hline 2927 & $\begin{array}{l}\mathrm{CH}_{2} \text { antisynmetric } \\
\text { stretching } \mathrm{f}\end{array}$ & 0.342 & \\
\hline 2899 & $\mathrm{CH}$ stretching & 0.346 & 0.350 \\
\hline 1430 & $\mathrm{CH}_{2}$ bending ${ }^{\mathrm{e}}$ & 0.350 & \\
\hline 1375 & $\mathrm{CH}$ bending ${ }^{\mathrm{e}}$ & 0.322 & 0.334 \\
\hline 1335 & $\mathrm{OH}$ in plane bending ${ }^{\mathrm{e}}$ & 0.300 & \\
\hline 1161 & $\mathrm{CO}$ (bridge $^{\mathrm{e}}$ & 0.304 & 0.334 \\
\hline 1108 & $\mathrm{CO}$ stretching ${ }^{\mathrm{e}}$ & 0.273 & 0.347 \\
\hline 1069 & $\mathrm{CO}$ stretching ${ }^{\mathrm{e}}$ & 0.304 & 0.352 \\
\hline 1029 & $\mathrm{CO}$ stretching ${ }^{\mathrm{e}}$ & 0.314 & 0.348 \\
\hline 899 & $\mathrm{Cl}$ group stretching ${ }^{\mathrm{g}}$ & 0.304 & \\
\hline 895 & $\mathrm{Cl}$ group stretching ${ }^{\mathrm{g}}$ & & 0.344 \\
\hline
\end{tabular}

a Molecular orientation factor $f^{\|}$estimated by eq 5

b Film cast from anisotropic solution

c Film cast from isotropic solution.

d Reference 24.

e Reference 25 .

f Reference 26.

${ }^{g}$ Reference 27. shows assignments and molecular orientation factor $f^{\prime \prime}$, calculated from eq 5 , of characteristic IR bands for a- and i-films in Figure 8. Slight difference in peak positions of IR band (for example, $\mathrm{OH}$ stretching region and $\mathrm{C}_{1}$ group stretching) between a-film and i-film was detected. Differences in dichroism of IR band between a-film and i-film are considerable. The IR band at $3475 \mathrm{~cm}^{-1}$ is responsible for the $\mathrm{O}_{3} \mathrm{H} \cdots \mathrm{O}_{5}{ }^{\prime}$ intramolecular hydrogen bond, ${ }^{24}$ (this peak could be detected although its intensity was very weak) showing weak parallel dichroism for a-films. The IR band at 3444 $\mathrm{cm}^{-1}$ shows parallel dichroism for both i-film and a-film. On the other hand, anti-symmetrical bridge $\mathrm{C}-\mathrm{O}$ vibration $\left(c a .1161 \mathrm{~cm}^{-1}\right.$ ), anti-symmetrical in-phase ring stretching vibration (ca. $1108 \mathrm{~cm}^{-1}$ ) and $\mathrm{C}-\mathrm{O}$ stretching vibration $\left(1069 \mathrm{~cm}^{-1}\right)$ show perpendicular dichroism for a-film, while these IR bands reveal parallel dichroism for i-film. The latter is commonly observed for stretched cellulose film made from isotropic solution.

Thus, the cellulose film recovered from the anisotropic solution system has unique molecular chain orientation different from the film prepared from isotropic solution. It is especially, interesting that the bridge $\mathrm{C}-\mathrm{O}$ vibration, which gives typical IR band characterizing the main axis of cellulose molecules, shows perpendicular dichroism while the $\mathrm{O}_{3} \mathrm{H} \cdots \mathrm{O}_{5}^{\prime}$ intramolecular hydrogen bond remains parallel to the shear direction (see Table I). Similar results have been already reported by the Okajima et $a .^{14}$ on lyotropic cellulose acetate $/ 70$ wt $\%$ nitric acid system. The distorted helical structure of a unit molecular chain of cellulose due to the intermolecular interaction is one possibility to explain the above.

\section{CONCLUSIONS}

An acid mixture with a specific composition (sulfuric acid/polyphosphoric acid/water $=c a$. $1 / 8 / 1, w / w / w)$ forms celulose liquid crystal with 
cholesteric structure as detected by circular dichroism and the cellulose is not derivatized in the system. A Raman spectroscopic study of the solvent mixture revealed that only at a specific composition, the hydrolysis of polyphosphoric acid proved to be restricted. A Polarized FT-IR study showed that both bridge $\mathrm{C}-\mathrm{O}$ and in-phase ring $\mathrm{C}-\mathrm{O}$ of the cellulose molecules in the film prepared from the anisotropic solution are perpendicularly orientated to the shear direction imposed on the mesophase.

\section{REFERENCES}

1. R. S. Werbowyj and D. G. Gray, Mol. Cryst. Liq. Cryst., 34, 97 (1976).

2. J. Maeno, Japanese laid open patent 52-96229(1977).

3. M. Panar and O. B. Willcox, Japan laid open patent 53-96229 272 (1986).

4. H. Chanzy and A. Peguy, J. Polym. Sci., Polym. Phys. Ed., 18, 1137 (1980).

5. E. Bianchi, A. Ciferri, G. Conio, A. Cosani, and M. Terbojevich, Macromolecules, 18, 646 (1985).

6. D. L. Patel and R. D. Gilbert, J. Polym. Sci., Polym. Phys. Ed., 19, 1231 (1981).

7. Y. S. Chen and J. A. Cuculo, J. Polym. Sci., Polm. Chem. Ed., 24, 2075 (1986).

8. K.-S. Yang, M. H. Theil, and J. A. Cuculo, in "Polymer Association Structures," ACS Symposium Series 384, M. A. El-Nokaly, Ed., The American Chemical Society, Washington, D. C., 1989, p 156.

9. I. Quenin, H. Chanzy, M. Paillet, and A. Peguy, in "Integration of Fundamental Polym. Sci. and Tech.,"
L. A. Kleinties and P. J. Lemstra, Ed., Elsevier Appl. Science Publishers., Amsterdam, Netherland, 1986, p 57.

10. J. P. O'Brien, U. S. Patent 4,464,323; 4,501,886 (1984).

11. K. Kamide and M. Saito, Eur. Polym. J., 20, 903 (1984).

12. K. Kamide, K. Okajima, T. Matsui, and S. Kajita, Polym. J., 18, 273 (1986).

13. S. Kajita and K. Okajima, Japan laid open patent 58-125701.

14. K. Okajima, T. Kuriki, S. Kajita, and K. Kamide, $J$. Text. Mach. Soc. Jpn., 42, T47 (1989).

15. T. Yamashiki, T. Matsui, M. Saito, K. Okajima, K. Kamide, and T. Sawada, Br. Polym. J., 22, 73 (1990).

16. W. Brown and R. Wikstrom, Eur. Polym. J., 1, 1 (1965).

17. H. de Vries, Acta Crystallogr., 4, 219, (1951).

18. K. Kamide and K. Okajima, Polym. J., 16, 857 (1984).

19. Y. Kobayashi and S. Okajima, Bull. Chem. Soc. Jpn., 27, 467 (1954).

20. G. H. Meeten and P. Navard, Polymer, 23, 1727 (1982).

21. T. Yamashiki, T. Matui, M. Saito, Y. Matuda, K. Okajima, K. Kamide, and T. Sawada., Br. Polm. J., 22, 201 (1990).

22. R. S. Werbowj and D. G. Gray, Macromolecules, 17, 1512 (1984).

23. T. Yamagishi, D. Eng. Thesis Kyoto University (1989), p 37.

24. J. Hayashi, A. Sueoka, and T. Watanabe, J. Chem. Soc. Jpn., 1320 (1974).

25. H. G. Higgins and C. M. Stewart, J. Polm. Sci., 51, 59 (1961)

26. R. Schneider and J. Vodnanski, Coll. Czech. Chem. Commun., 28, 2060 (1963).

27. R. T. O'Corner and E. F. Dupre, Text. Res. J., 28, 382 (1958). 